rev.relac.int.estrateg.segur.7(2):97-130,2012

\title{
LA IMPORTANCIA DEL ACCOUNTABILITY SOCIAL PARA LA CONSOLIDACIÓN DE LA DEMOCRACIA EN AMÉRICA LATINA*
}

\author{
Magda Catalina Jiménez ${ }^{* *}$
}

\section{RESUMEN}

El accountabilty se ha convertido en un tema de interés no sólo para indagar el grado de control de la política y de quienes la ejercen, sino en un indicador sobre la calidad de la democracia. Así, dentro de la rendición de cuentas, el accountabilty social podría entenderse como una forma de fortalecimiento de la política, debido a que en ella existe una profunda interrelación entre gobierno, instituciones, ciudadanos y medios de comunicación. Por lo tanto, este artículo reflexivo busca hacer un primer análisis sobre el desarrollo de esta forma de control político en Latinoamérica, con el fin de establecer si existe una correlación entre esta práctica y los indicadores de democratización de la región.

Palabras clave: Accountability, Movilización, Participación, Ciudadanía, Calidad de la democracia, Latinoamérica.

* El presente artículo hace parte del proyecto "La calidad de la democracia en Colombia: partidos políticos y movimientos sociales, adscrito al Centro de Investigaciones y proyectos especiales CIPE, Facultad de Finanzas, Gobierno y Relaciones Internacionales de la Universidad Externado de Colombia.

** Máster Estudios Latinoamericanos, Universidad de Salamanca.

Correo electrónico: magda.jimenez@uexternado.edu.co 


\title{
SOCIAL ACCOUNTABILITY AND QUALITY OF DEMOCRACY: A NECESSARY RELATION
}

\begin{abstract}
Accountabilty has become a topic of interest not only to investigate the degree of control of politics and its practitioners, but an indicator of the quality of democracy .Thus, within accountability, social accountabilty could be understood as a way of strengthening policy, because in it a profound interplay between government, institutions, citizens and media. Therefore, this article seeks to make a first reflective analysis on the development of this form of political control in Latin America, in order to establish whether a correlation exists between this practice and the democratization indicators in the region.
\end{abstract}

Key words: Accountability, Mobilization, Participation, Citizenship, Quality of democracy, Latin American.

\section{A IMPORTÂNCIA DO ACCOUNTABILITY SOCIAL PARA A CONSOLIDAÇÃO DA DEMOCRACIA NA AMÉRICA LATINA}

\section{RESUMO}

O accountabilty tornou-se um tema de interesse não só para investigar o grau de controle da política e de seus praticantes, mas também como um indicador da qualidade da democracia. Sendo assim, dentro da prestação de contas, o accountabilty social poderia ser entendido como uma forma de fortalecer a política, porque nele há uma relação profunda entre governo, instituições, cidadãos e mídia. Portanto, este artigo reflexivo pretende fazer uma primeira análise do desenvolvimento dessa forma de controle político na América Latina, a fim de determinar se existe uma correlação entre essa prática e os indicadores de democratização da região.

Palavras-chave: Accountability, Mobilização, Participação, Cidadania, Qualidade da democracia, América Latina.

\section{INTRODUCCIÓN}

Aunque el proceso de transición a la democracia que experimentó Latinoamérica ha sido satisfactorio respecto al mantenimiento de reglas para asegurar el respeto a la institucionalidad, los problemas que se han presentado en algunos de sus sistemas políticos demuestran falencias no sólo en el proceso de democratización mismo, sino en la representatividad de las demandas a través de las instituciones diseñadas para ello. 
Estos déficits en la democratización visibilizan no sólo problemas en la representación política, sino en la efectividad de lo que se denomina mecanismos de control. En el caso del accountability vertical en su dimensión electoral, "la causa puede encontrarse en sistemas de partidos poco estructurados, alta volatilidad de los partidos y votantes y cambios abruptos en las orientaciones de las políticas públicas" (O’Donnell, 1998, p. 3). Respecto a la efectividad del accountability horizontal, la fuerza del presidencialismo ha debilitado el sistema de pesos y contrapesos institucionales de forma importante; además, el débil arraigo del imperio de la ley y defensa del interés público, pueden ser causas explicativas de la debilidad de este mecanismo. En ese orden de ideas, el accountability social se ha estructurado como una herramienta de control de la política, estructurado a partir de organizaciones de la sociedad civil, movimientos ciudadanos y otro tipo de grupos significativos con el fin de ejercer supervisión sobre el mandato representativo.

Este artículo pretende hacer una reflexión sobre como el accountability social y su fortalecimiento en los últimos años, ha potencializado las formas de participación política de los ciudadanos no sólo frente al proceso de implementación de políticas públicas, sino a las formas de movilización social, activando otro tipo de controles institucionales que han venido fortaleciendo los indicadores en los que se inscribe la calidad de la democracia en la región.

El texto se estructuró a partir de una variable dependiente el fortalecimiento del accountability social y dos variables independientes: la primera, la participación política sustentada en el aumento de la movilización ciudadana a partir de estructuras no institucionales. La segunda, la consolidación de la democracia sustentada desde la calidad de la misma. Es importante señalar unas variables interdependientes como la gobernanza y cultura política, presentes en algunos apartes del texto.

De acuerdo con lo anterior, el trabajo se ha estructurado en cuatro secciones. La primera es de carácter conceptual donde se desarrolla el concepto de accountability y calidad de la democracia. Después se abordara el concepto de accountability social y se visibilizan algunos casos en los que este mecanismo ha sido determinante para el fortalecimiento de mecanismos democráticos. La tercera parte establece la relación entre este mecanismo y la calidad de la democracia en Latinoamérica. Por último, se darán las conclusiones generales.

\section{PRECISANDO ALGUNOS CONCEPTOS}

El concepto de accountability está profundamente relacionado con la democracia representativa. En ese sentido, los gobiernos representativos combinan un marco institucional de autorización del poder con uno orientado a asegurar la responsabilidad y receptividad de los agentes autorizados, de manera que como afirma Peruzzotti (2008, p.3), este se ajusta a la legalidad y su decisión refleja las diversas demandas ciudadanas. La construcción de este vínculo entre 
gobernantes y gobernados basado en la libre representación, requiere del establecimiento de confianza y autonomía en la delegación electoral, sin que esto signifique una total desafección de los ciudadanos al ejercicio decisorio de los funcionarios. Para reducir esta brecha, la democracia representativa necesita dispositivos de control que aseguren que los gobiernos cumplan dentro de la legalidad con las políticas para las que han sido escogidos.

En ese orden de ideas, la cuestión central de este concepto "Hace referencia a la capacidad para asegurar que los funcionarios públicos rindan cuentas por sus conductas; es decir, que estén obligados a justificar e informar sobre sus decisiones" (Schedler, 1999, p. 25). Así, los mecanismos de control cumplen un papel fundamental, razón por la cual se requiere la conformación de un sistema institucional con mecanismos de fiscalización, control y sanción eficientes.

El accountability contiene dos dimensiones conceptuales básicas: el answerability y el enforcement. La primera se refiere a la obligación de los funcionarios y políticos de informar acerca sus decisiones y justificarlas públicamente. Sin embargo, esto no supone la simple transmisión de información del Estado a la ciudadanía, requiere la formación del debate público donde se establece un proceso reflexivo así como la transparencia en la gestión y el derecho ciudadano, al acceso a la información pública (Peruzzotti, 2008). Para autores como March y Olsen (1995), la inteligencia política de la democracia descansa en el desarrollo de instituciones capaces de generar y utilizar el accountability para generar decisiones colectivas sabias.

La segunda dimensión resalta la existencia entre la rendición de cuentas y la sanción, al entenderse como la capacidad de imponer castigos a aquellos funcionarios que hayan violado sus deberes o incumplido sus obligaciones. Sin castigos efectivos, la rendición de cuentas que se desarrolla en las democracias es inocua y débil (Hernández y Arciniegas, 2011, p. 26). Sin embargo, esta dimensión puede incluir también un sistema de recompensas a la buena gestión, en la cual existen incentivos institucionales y simbólicos que permite a los funcionarios como defiende Ackerman (2006), tanto la aceptación de este control como mayor receptividad de los políticos para escuchar a la ciudadanía.

Las dos dimensiones en las que se enmarca el accountability corresponden tanto a lo legal como social y van intrincadas en el proceso de ejercicio del poder. Autores como Andreas Schedler (2008, p. 27), consideran que el accountabilty en las democracias modernas cumplen la función de "incomodar al poder, razón por la que es necesario no sólo la voluntad política para que estos se sometan de forma voluntaria a estos mecanismos, sino la habilidad de los ciudadanos de demandar información y presionar cuando sea necesario las sanciones de conductas inapropiadas"

El accountability legal busca que las acciones de los funcionarios estén enmarcadas en una estructura legal con mecanismos constitucionales o procedimientos administrativos que aseguren que los gobiernos respeten la ley y el debido proceso. Esta forma de accountability se guía 
por una lógica "basada en la rectitud, los actores políticos son juzgados sobre la base del cumplimiento de procedimientos considerados correctos en tanto se ajustan a procedimientos legales establecidos" (March y Olsen 1995, p. 154). En otras palabras, es necesario un sistema legal con capacidad de imponer la ley para que esta noción de accountability sea posible. De otro lado, el accountabilty político puede ser entendido como la capacidad que tiene el electorado para hacer que "las políticas gubernamentales respondan o se adecuen a sus preferencias" (Peruzzotti y Smulovitz, 2002, p. 27).

En esa medida, el accountability político está conectado con las elecciones y la representación. Un gobierno es políticamente responsable (accountable) "si los ciudadanos tienen medios para castigar administraciones irresponsables o a aquellas cuyas políticas no responden a las preferencias del electorado (unresponsive)" (Smulovitz et al., 2002, p. 27). Autores como Manin, Przeworski \& Stokes (1999), sostienen que las elecciones son las instituciones que pueden llevar adelante este tipo de control; así, la rendición de cuentas en el plano legal y político se pueden operacionalizar de acuerdo al eje de operación de las instituciones de control a través de mecanismos verticales y horizontales.

El mecanismo del accountability vertical es el resultado de unas elecciones limpias e institucionalizadas, a través de los cuales los ciudadanos "hacen responsables a los gobiernos de los resultados de sus acciones" (Barreda, 2010, p. 4), Por lo tanto, los ciudadanos a través del voto pueden premiar o castigar a los gobernantes. Con el voto prospectivo el votante puede escoger a buenos políticos que conllevan buenas políticas mientras que con el voto retrospectivo se reclama a los gobernantes sus acciones del pasado y el cumplimiento de los contenidos programáticos defendidos en campaña. Esto obliga a los gobernantes a "anticipar el juicio del electorado cuidando el buen desempeño del ejercicio de su gobierno para contar con el favor del ciudadano en las próximas elecciones" (Hernández et al., 2011, p. 29).

El accountabilty horizontal, noción creada por Guillermo O’Donnell se refiere a la existencia de "agencias estatales que tienen autoridad legal y están fácticamente dispuestas y capacitadas para emprender acciones que van desde el control rutinario hasta sanciones legales en relación con actos u omisiones de otros agentes o agencias del Estado que pueden, en principio o presuntamente ser calificadas como ilícitas o ilegales" (O'Donnell, 2002, p. 88). Este control es ejercido a través del sistema de pesos y contrapesos entre los poderes del Estado (ejecutivo, legislativo y poder judicial); sin embargo, estas relaciones intraestatales pueden sufrir desbalances cuando una considera que la otra ha sobrepasado su jurisdicción.

Cuando esta situación se presenta, se denomina un caso de accountability horizontal de balance (O’Donnell, 2004, p. 21). Para verificar la efectividad de los límites del accountability horizontal, se han creado diversas agencias de lo que se ha denominado accountability horizontal asignado, como "veedurías, fiscalías, contralorías, auditorías encargadas como se ha dicho en líneas 
anteriores de supervisar, prevenir y disuadir de otras instituciones estatales, nacionales o subnacionales (O' Donnell, 2004, p. 22).

El crecimiento y en algunos casos fortalecimiento de estas herramientas ha permitido un control a la burocracia, la cual permite con cuentas y procedimientos internos que en caso de violaciones "puedan desencadenar un proceso legal que contenga el poder de la burocracia" (Avritzer, 2002, p. 142). La fortaleza del llamado accountability administrativo depende de factores como "el proceso de formación de una burocracia centralizada y profesional, el patrón de establecimiento de un debido proceso, respeto de la ley y efectividad del sistema legal los cuales se estructuran paralelo al proceso de democratización" (Avritzer, 2002, pp. 142-143).

Ahora bien, mientras el accountability horizontal necesita para su efectividad de una alta capacidad de recursos institucionales internos, el accountability vertical necesita de un agente social externo como es el electorado, el cual indica que estos mecanismos de rendición de cuentas necesitan no sólo de instituciones consolidadas, sino de una sociedad civil y una cultura política capaz de que estos intercambios y controles garanticen el fin de los déficits democráticos. Es aquí donde surge por parte de los politólogos argentinos Catalina Smulovitz y Enrique Peruzzotti una interpretación complementaria al accountability vertical que han denominado accountability social el cual es ejercido a través de acciones de diferentes grupos de la sociedad civil o incluso individuos, con "el objetivo de dar a conocer errores gubernamentales, introducir nuevas demandas en la agenda pública o activar el funcionamiento de las agencias de control horizontal" (Barreda, 2010, p. 5).

En sociedades como la latinoamericana, con bajos niveles educativos, desigualdad, pobreza y debilidad institucional, los procesos de democratización han "permitido una ola de creación y fortalecimiento de organismos estatales autónomos de rendición de cuentas, junto con el desarrollo de organizaciones, redes e iniciativas ciudadanas que han empoderado a la ciudadanía" (Hernández et al., 2011, p. 34). Esto se refleja en los indicadores en los que se mide la calidad de la democracia, concepto donde hay consenso en cuanto a su definición.

La democracia es medible en países que tienen un mínimo grado de democratización como es el caso de Latinoamérica. En ese sentido, encontramos dos ópticas sobre esta temática; la primera, más procedimental, se basa en la noción de poliarquía de Dahl ${ }^{1}$ en la que la democracia y su calidad puede explicarse a través de una serie de procedimientos que controlan la forma en que se accede al poder. La segunda se enmarca en términos más ingénitos "ya que esta no sólo

1. De acuerdo a Robert Dahl, la poliarquía contiene ocho dimensiones institucionales: libertad de asociación y organización, libertad de pensamiento y expresión, derecho al sufragio activo y pasivo, derecho a competir con el apoyo electoral, fuentes alternativas de información accesible, elecciones libres e imparciales que produzcan mandatos limitados y existencia de instituciones que controlen y hagan depender las políticas gubernamentales del voto y de otras expresiones de preferencias. 
implica los procedimientos sino también los objetivos y resultados que se pretenden alcanzar, tales como el desarrollo económico, la justicia social o la igualdad" (Barreda, 2011, p. 268).

Otros autores como Levine y Molina (2007, p. 19), entienden que la calidad de la democracia depende tanto del funcionamiento de los procesos mediante los cuales la población selecciona y controla sus líderes políticos, así como el contexto social en que funciona. Así, se pueda evaluar el grado en que individuos y organizaciones tienen posibilidades de acceso a la participación de manera libre e igual. Esta interpretación de la calidad de la democracia toma en consideración a la sociedad civil y las condiciones de organización y control que estas pueden producir dentro de un marco institucional. Así, la democracia es también "un modo particular de relación, entre Estado y ciudadanos y entre los propios ciudadanos, bajo un tipo de estado de derecho que, junto con la ciudadanía política sostiene la ciudadanía civil y una red completa de rendición de cuentas" (O Donnell, 2001, p. 27).

Entre una y otra interpretación sobre la calidad de la democracia, los estudios han incluido en su lista de criterios de medición al accountability. Diamond y Morlino en su estudio del 2004, incluyen tanto el vertical como el horizontal. Hagopian lo relaciona en términos de representación y Levine y Molina incluyen no sólo el vertical y horizontal sino el social, a través de la dimensión responsabilidad, la cual puede ser formal e informal. La formal se encuentra institucionalizada en "leyes y normas administrativas donde existe el poder potencial de imponer sanciones" (Levine y Molina, 2007, p. 26), mientras la responsabilidad informal se dirige a movilizar la ciudadanía para ejercer presión pública para que se sancione a los funcionarios. Por lo tanto, el accountability social es un fenómeno que merece un análisis más detallado, debido a "los efectos positivos que ha tenido en el desempeño de gobiernos y mejoramiento de la calidad de la democracia, no sólo por la defensa de los derechos humanos, sino porque representan un movimiento de defensa de lo público" (Hernández et al., 2011, p. 39).

\section{2. ¿QUÉ ES EL ACCOUNTABILITY SOCIAL?}

En los últimos años se ha venido consolidando dentro de los mecanismos de rendición de cuentas el accountability social. Este puede considerarse como "una forma vertical de control de las autoridades políticas, basado en las acciones de un amplio espectro de asociaciones y movimientos ciudadanos, así como en acciones mediáticas" (Smulovitz et al., 2002, p. 32). A través de estos mecanismos, grupos de ciudadanos estructurados a partir de diversas organizaciones fiscalizan la gestión de la administración pública, denuncian actos de corrupción o presentan propuestas para la adopción de políticas públicas.

Esta forma de control no depende del aspecto electoral, sino que recoge la experiencia social y ciudadana de la movilización proceso que Sidney Tarrow (1998, p. 185) Ilama estructuras de reserva, así como las acciones de los grupos organizados y medios de comunicación, 
interesados en influir en el sistema político. Además, tal como afirma Peruzzotti $(2002$, p. 33) este puede ejercerse entre elecciones y no depende de calendarios fijos como sucede con el proceso electoral.

Algunos cuestionamientos surgen sobre este mecanismo: qué controla, cómo controla y cómo sanciona. Respecto al primer interrogante, las organizaciones civiles se organizan en torno a demandas que exigen el cumplimiento de los procedimientos institucionales de los organismos involucrados; de esta forma se visibilizan y denuncian ante la opinión pública los actos gubernamentales ilegales alertando a las entidades institucionales encargadas de vigilarlos.

En cuanto a cómo controla, este se refiere a la persecución de metas al permitir un control selectivo de la política, funcionario o gestión, usando para ello un amplio repertorio de acciones colectivas, que incluye un elevado uso de los medios de comunicación con el fin de que los ciudadanos puedan especificar si están sancionando una conducta ilegal o señalando agendas alternativas" (Smulovitz et al., 2002, p. 34). Respecto a cómo sanciona, este se enmarca dentro de la teoría de la salida de la $\mathrm{voz}^{2}$, que da a este tipo de mecanismos capacidades para sanciones simbólicas que conllevan un elevado costo político, entendido desde lo reputacional.

En otras palabras, se trata "de una voz que espera y demanda ser oída, en el sentido de que tal o cual agencia estatal adopte las decisiones a las que ella se refiere" (O 'Donnell: 2002, p. 96). Además, las acciones del accountability social puede activar a las instituciones con capacidad de ejercer sanciones, al permitir no sólo la visibilización de las problemáticas sino la activación de mecanismos de control verticales -electorales y horizontales. En ese orden de ideas, el accountability social funciona de forma interdependiente con otros mecanismos de control, permitiendo acciones distintas por parte de funcionarios e instituciones y redefiniendo la relación entre ciudadanía y representantes políticos. Y es precisamente el debilitamiento de la representación política la situación que ha permitido una mayor acción y fortalecimiento de este mecanismo.

Si asumimos -como afirma Bernard Manin (1998)- que la representación se estructuró a partir de cuatro principios: primero, gobernantes elegidos por gobernados; segundo, conservación de cierto margen de independencia de los gobernantes con relación a los gobernados tercero, una opinión pública respecto a temas políticos que se expresa más allá del control de los gobernantes

2. El economista Albert Hirschman desarrolla una teoría que pretende explicar el comportamiento del individuo a través de tres elementos: lealtad, salida y voz. En ella argumenta que el individuo tiene tres opciones frente a las fallas o desequilibrios que se pueden presentar en un entorno económico o político. La salida, que es cuando los clientes o ciudadanos deciden abandonar el mecanismo en falla; la voz que se presenta cuando los individuos deciden hablar directamente a través de mecanismos institucionales y en ocasiones violentas si la salida no es una opción viable, y por último la lealtad, en la que deciden quedarse acatando los desequilibrios tal como están. Hirschman, A. (1979). Salida, voz y lealtad. México.: Fondo de Cultura Económica. 
y, por último, decisiones políticas que derivan de la deliberación, podemos afirmar que en Latinoamérica el empoderamiento en el que se ha inscrito la sociedad civil en las últimas décadas, ha venido cuestionando las demarcaciones del contrato representativo, demostrando que la confianza, en la cual debe estructurarse la representación política, es uno de los elementos centrales del accountability social.

De esa forma, la confianza no sólo en los representantes, sino en las instituciones y sus procedimientos es lo que las instituciones sociales y civiles quieren activar. Si bien existen elecciones que habilitan a los políticos, persisten debilidades "en la red de agencias capaces de controlar y castigar las acciones que puedan llegar a ser calificadas como ilegales o corruptas. Este déficit es el blanco central de esta nueva forma de activismo cívico" (O Donnell 1999, p. 46), que busca restablecer la confianza como un valor imperante y permanente en el sistema democrático, frente a la deteriorada imagen de los partidos políticos que han profesionalizado sus acciones dando lugar a una serie de partidos estructurados sólo en el momento de las elecciones. Esta democracia de sondeo (Sartori, 2003) construye partidos con una organizaciones e identidades débiles que crean sus programas a partir de la oferta de los medios de comunicación.

Así, el accountability social retorna a los sistemas políticos el tema de la confianza, una especie de "institución invisible" que cumple tres funciones de acuerdo a Rosanvallon (2007, p. 23); en primer lugar amplía la calidad de la legitimidad al añadir una dimensión moral (integridad en sentido amplio) y una sustancial (preocupación por el bien común). En segundo lugar, le da a este un carácter temporal (se mantiene como un valor en el tiempo) por último, es un fin economizador institucional. Por lo tanto, la práctica del accountability social incide en todas las esferas del poder público, debido a la triple estrategia en la que se estructura: jurídica, movilizacional y mediática (Peruzzotti: 2002. p. 44). Aunque las estrategias pretenden ir de forma sincrónica, de acuerdo al caso, una de las tres será la más significativa.

Si bien esta estrategia utiliza la institucionalidad, es necesario también un grado de movilización de parte de los ciudadanos es decir, el uso de repertorios de acción capaces de hacer conocer dentro de la esfera pública la demanda o situación en la que se quiere incidir. En esa medida, lo que importa en lo movilizacional no es tanto la medición respecto al grado de resistencia entre opositores, sino la forma en que el repertorio de acción usado por parte de los grupos y asociaciones, logra crear una estrategia en la que la decisión que pueda implementarse por parte del funcionario, signifique una erosión en su capital político o social, de forma tal, que el costo a largo plazo es muy alto para mantener esta situación.

Nos enfrentamos entonces a una especie de "ciudadano vigilante", con una funcionalidad específica en su forma de protestar, ya que no buscan sólo visibilizar la situación, sino que la novedad se entiende desde su forma de organización en la que las acciones de vigilancia, denuncia y calificación se conviertan en los tres ejes desde donde se construye lo movilizacional. En ese orden de ideas, estos grupos se han organizado como comités de vigilancia 
(Watchdogcomittes), produciendo "efectos de autoridad capaces de modificar y coaccionar la conducta de aquellos que tienen como blanco" (Rosanvallon, 2007, p. 77), ya que no tienen por objeto representar a sectores poblacionales con demandas específicas, sino enfrentarse a situaciones. En otras palabras, su interés no es tomar el poder sino influenciarlo.

A través de una estrategia mediática organizada y consistente, los grupos y asociaciones vigilantes informan a la opinión pública sobre las situaciones a las que se enfrentan: corrupción, procesos judiciales, abusos por parte de funcionarios públicos entre otros. Asistimos a una relación de máxima ganancia entre los medios y las iniciativas ciudadanas, que puede contener dificultades respecto al derecho a la privacidad o inclusive a mostrar a los actores involucrados en el hecho como culpables hasta que demuestren lo contrario. Así, los medios incluyendo Internet y redes sociales actuales como Facebook, Twitter o Instagram, se convierten por su conformación como red, en "una herramienta fundamental para esta práctica política, debido a sus funciones de vigilancia, denuncia y calificación (Rosanvallon, 2007, p. 81). Por lo tanto, la estrategia mediática que plantea el accountability social permite que el movimiento o las organizaciones tengan cierto nivel de decisión sobre el desarrollo de las estrategias que plantean los medios para que la práctica resulte exitosa.

Al considerar que no tenemos un ciudadano pasivo, el accountability social surge como una práctica con un potencial importante dentro de sistemas políticos complejos respecto a la consolidación de la democracia y su calidad, ya que el tema del accountability social es importante en muchas democracias latinoamericanas debido a que la institución política que alguna vez fue el instrumento fundamental del control ya no cumple su función: los partidos políticos (Przeworski, 2002, p. 79). Si bien el accountability social no pretende remplazar a los partidos políticos, su ejercicio contribuye al fortalecimiento de la institucionalidad, no sólo por los actos de control a actuaciones ilegales o corruptas, sino que su contribución ayuda a la reformulación tanto de las formas representativas como de los mecanismos de rendición de cuentas en general.

Así, este tipo de accountability se inscribe como un dispositivo alternativo que demuestra la debilidad de los mecanismos de control vertical y horizontal en la región y la imperativa necesidad de reformular un sistema de controles mejor diseñado y con sanciones efectivas a los involucrados en los procesos detectados por los participantes; por lo tanto, el accountability social "representa un importante elemento de estimulación para que ciertas agencias de accountability horizontal se resuelvan a asumir sus arduas responsabilidades" (O 'Donnell, 2002, p. 93 - 94).

El accountability social puede enmarcarse entonces como una práctica dentro de lo que Rosanvallon (2007) Ilama espíritu de control democrático, la cual resulta de los efectos de influencia mutua que ejercen los militantes y ciertos sectores de los agentes públicos separándose de los grupos de presión o grupos de interés, establecidos dentro del sistema político. 
En este sentido, las acciones de estos grupos se "expresan de forma importante en un lenguaje de derechos y legalidad" (O’Donnell, 2002, p. 95). De esta forma, puede ser considerado como un mecanismo de participación, en la medida en que ha representado una forma primordial de politización que sirve para probar si la conducta de los representantes políticos y los funcionarios no electos, se adecúa o no a los principios normativos que dan legitimidad al contrato representativo (Peruzzotti, sf, p. 15).

Para finalizar, lo que busca el accountability social es una democracia que no puede fortalecer y mejorar su calidad sino "integra en su definición sus riesgos de mal funcionamiento y no prevé entre sus instituciones, el medio para criticarse a sí misma" (Rosanvallon, 2007, p. 85). Así, es importante escuchar y dar respuesta a las demandas cívicas, de tal forma que los mecanismos de control puedan ser no sólo eficientes sino que permitan afianzar la confianza por parte de los ciudadanos en el contrato representativo.

\subsection{EJEMPLO DE ACCOUNTABILITY SOCIAL EN AMÉRICA LATINA}

Gracias a los cambios constitucionales que experimentó la región durante la década de los noventa, se llevaron a cabo reformas institucionales y jurídicas que buscaron garantizar no solo la protección a los derechos humanos, sino un fortalecimiento del poder judicial tanto en el acceso ciudadano como en la efectividad temporal de los procesos. Este fortalecimiento se ha convertido en uno de los pilares a través de los cuales "las agrupaciones cívicas, y organizaciones no gubernamentales (ONG's) formulan reclamos, obligando al Estado a intervenir en aquellas disputas políticas y sociales que los funcionarios públicos prefieren evitar o ignorar" (Peruzzotti, 2002, p. 246). Ejemplo de ello es la acción de tutela en Colombia o el uso del poder judicial en Bolivia por parte de organizaciones indígenas en torno a reclamaciones de tierras.

En ese orden de ideas, la sociedad civil latinoamericana ha estimulado una mayor actividad e interés en el diseño y organización del sistema político, ya que como afirma Seymour Lipset (1994, p. 24) una sociedad civil completamente operativa seguramente también será participativa. De esta forma, "la construcción de la democracia es un proceso de institucionalización del conflicto" (Weffort, 1992, p. 111), en el que la ciudadanía y las instituciones se encuadran dentro de las normas de responsabilidad y responsiveness que legitiman la representación e inciden dentro de las decisiones gubernamentales.

En ese sentido, lo que debe estudiarse no es sólo las formas de participación sino "las mutaciones de la actividad democrática" (Rosanvallon, 2007, p. 36), debido a que el voto aunque sigue siendo fundamental dentro de los sistemas políticos democráticos, no es suficiente para mantener su eficiencia, calidad y garantías. Por ello, la mutación a la que hemos hecho referencia se evidencia en la estructura de la expresión, implicación e intervención, desmitificando la idea de una ciudadanía pasiva. 
Con sectores ciudadanos activos y dispuestos a incidir en el sistema político, diversos casos de accountability social se han presentado en Latinoamérica en la última década, clasificados a través de tres momentos de activación: producida por escándalos políticos, por políticas públicas y por efectos de movilización.

2.1.1 Activación producida por escándalos políticos. Aquí se clasifican aquellas situaciones en la cual los medios de comunicación fueron el dispositivo central que permitió la visibilización de un escándalo que puso en marcha mecanismos de accountability social y horizontal. En julio de 1992, en el comienzo del gobierno de Alberto Fujimori, nueve estudiantes y un profesor sospechosos de pertenecer al movimiento guerrillero Sendero Luminoso fueron secuestrados en el campus de la Universidad Nacional de Educación por parte de un grupo especial del ejército peruano llamado por los periodistas como "grupo Colina".

La desaparición tortura y posterior asesinato de estas personas se dio en pleno auge del conflicto entre el grupo guerrillero y el gobierno peruano, donde fue común la violación a los derechos humanos y el uso de acciones violentas por parte de las fuerzas de protección institucionales. Los hechos hubieran quedado como una estadística más, sino es por el director de la Revista Sí, Ricardo Uceda, quien denunció ante la opinión pública peruana los dramáticos acontecimientos. Para sustentar la denuncia, los periodistas usaron documentación entregada por las mismas Fuerzas Armadas, que permitió a los periodistas encontrar los huesos calcinados y restos de ropas de los ejecutados.

El escándalo político que desató la publicación le dio la razón al Congresista Henry Pease, quien había denunciado los hechos en 1993 en el Congreso Nacional, hecho que le valió al Congreso una amenaza velada por parte del General del Ejercito General Nicolás Hermoza que cerró filas junto con el partido oficialista para debilitar la Comisión de Investigación que se estaba considerando. Ante el poder de la evidencia y las implicaciones que el escándalo podría traer en otras esferas del gobierno, tuvo que aceptar el enjuiciamiento de los militares solo a través del fuero militar.

La activación de mecanismos de accountability social y horizontal en este caso, fue posible gracias a la capacidad de denuncia de los medios de comunicación, situación que permitió gracias al trabajo del fiscal, un curso de investigación correcto al cual se debe sumar la presión ejercida por los colectivos de derechos humanos nacionales e internacionales. Todo esto señala que los medios de comunicación pueden ser un instrumento fundamental para el desarrollo de diversos mecanismos de accountability, en "la medida en que obligó al gobierno a reconocer el hecho y castigarlo, cerrando el asunto con un saldo a favor de la democracia" (Lynch, 2002, p. 274 - 275).

Otro caso destacable de activación por escándalo lo encontramos en los hechos acaecidos durante el gobierno de Saúl Menem. En 1995 medios de comunicación, partidos políticos de 
oposición y fiscalía, acusaron a diversos sectores de las Fuerzas Armadas de planificar la venta de setenta y cinco toneladas de armas a Ecuador. Sin embargo, esto era parte menor de una operación de enormes proporciones que incluyó "la venta de 6.500 toneladas de armamento a Croacia en pleno conflicto de los Balcanes, situación que quebrantaba el embargo impuesto por las Naciones Unidas" (Waisbord, 2002, p. 289-290). El escándalo del cual todos afirmaban pasó a sus espaldas, tomó enormes proporciones cuando el diario El Clarín publicó un decreto firmado por el Presidente Menem y varios Ministros aprobando la venta de armas a Venezuela y Panamá, así como otros decretos secretos donde se autorizaban múltiples envíos de armas entre 1991 y 1995.

La pérdida reputacional y las implicaciones simbólicas y electorales que podría traer al gobierno peronista este caso, no detuvo los intentos oficialistas por detener la investigación y entorpecer los mecanismos judiciales y administrativos adscritos a ella. Si bien se activaron mecanismos horizontales como renuncias y audiencias en el Congreso, también llegaron a la esfera judicial. En este caso con una confesión del ex interventor de Fabricaciones militares, Luis Sarlenga así como la prisión domiciliaria en 2001 del ex presidente Carlos Menem.

Si bien en el caso peruano el escándalo político fue más efectivo en la activación de mecanismos de control social y horizontal que en el argentino, en los dos se evidencia el uso de una estrategia mediática organizada y consistente, respaldada en medios de comunicación de enorme cobertura y legitimidad que se erigieron como dispositivo principal no solo de denuncia sino de control de los funcionarios y su posterior proceso judicial y político. Así, "las noticias acerca de comportamientos ilegales de funcionarios no solo tienen una ventaja sustancial sobre otras notas, sino que afectan a los ciudadanos en cuanto al funcionamiento de la democracia" (Lynch, 2002, pp. 310 y 320$)$.

2.1.2 Activación producida por políticas públicas .Uno de los aspectos más interesantes del proceso de democratización en Latinoamérica ha sido la inclusión de la ciudadanía en el proceso de las políticas públicas. Allí, la cuestión de la legitimidad y eficacia nos remite a la necesidad de los gobiernos de contar "para su operativa con actores cívicos, sociales e inclusive empresariales que ponen sobre la mesa la aparición de nuevas formas de participación ciudadana donde se estructura una relación diferente entre Estado, mercado y sociedad civil" (Jiménez, 2009. p. 14). Por lo tanto, es en el proceso de formulación e implementación de la política pública, donde se activan los dispositivos de accountability social que vigilan y controlan que el "Estado no transgreda las reglas de acuerdo acordadas" (Isunza, 2011, p. 69).

Para que estos mecanismos tengan cierto grado de efectividad, se requiere un grupo de organizaciones ciudadanas articuladas en torno a demandas puntuales pero con cierto grado de organización interna sea esta vertical u horizontal. Esto les permite tener recursos simbólicos y materiales suficientes para establecerse como actores significativos en el proceso de formulación e implementación de las políticas. Esta visión de la política pública en la que el accountability 
social tiene mayor capacidad de incidencia, se aleja de los modelos de formulación clásicos del top down, que suponen tanto el acatamiento de la administración pública al poder político como un "sesgo legalista en la medida en que se focaliza en la implementación de normas legales" (Roth, 2008, p. 2).

Al incluir a los ciudadanos en el ciclo de las políticas públicas, el control también se encuentra en manos de la sociedad. Esto hace que en el diseño de la política las demandas o necesidades de los colectivos sean incluidas tanto en lo normativo como en los dispositivos para su operacionalización. Además, visibilizan a la administración las falencias normativas o procedimentales que se puedan tener, estimulando así otros mecanismos de accountability horizontales y administrativos. Ejemplo de este tipo de accountability fueron los presupuestos participativos de la ciudad de Porto Alegre en Brasil en 1989.

En una ciudad con importantes niveles de desigualdad en sus 16 regiones y con un presupuesto escaso, el partido de los trabajadores (PT) logró ganar las elecciones "con el lema "administración popular" e "inversión de prioridades", y mediante una reforma fiscal aumentó su capacidad de recaudación y de gasto" (Pérez, 2003, p. 6). Con recursos externos favorables como fue el nuevo gobierno municipal, las organizaciones comunitarias y asociaciones de moradores que se habían conformado desde la década de los ochenta, tuvieron una estructura de oportunidad política para incidir en el diseño presupuestal el cual "había sido identificado por parte de algunas organizaciones populares como un campo significativo de intervención social y política" (Pérez, 2003, p. 5). Así, gobierno y organizaciones sociales a través de reuniones regulares estructuradas en asambleas horizontales, deliberaban sobre la priorización de los recursos presupuestales articulados en diversas temáticas que son enviadas a la Prefectura Municipal para que hagan parte del presupuesto del año siguiente.

El aprovechamiento de las experiencias organizativas de los actores sociales evidencia un alto grado de capital social entre los componentes de la organización, con "un repertorio de civismo acumulado por una sociedad para satisfacer necesidades y expectativas" (Ibarra, 2002, p. 62), situación que resulta efectiva para ejercer diversos mecanismos de control. Así, de acuerdo a Putnam (1993) esta estrategia sería reconstructora de altos rendimientos institucionales de bienestar.

Por lo tanto, la interacción de los actores en el diseño presupuestal fue posible gracias también a diversos dispositivos de accountability horizontal incluidos en la Constitución de 1988, donde se apostó por la "cogestión de las políticas sociales entre el Estado y la sociedad civil, de manera descentralizada y articulada" (Isunza, 2011, p. 64). De esta forma, en el proceso de formación del presupuesto, también existe espacio para discutir los problemas y acciones de solución que deben articularse en los procesos de formulación e implementación de las políticas.

Es importante señalar que esto no debe depender solo de una oportunidad política favorable, también del grado de institucionalización que logren tanto los actores como los mecanismos de 
control involucrados en ese proceso, sin que esto signifique para los colectivos "la pérdida de su sentido de participación con formas irrelevantes o higienizadas que solo sirven para legitimar un sistema gracias a la moderación de la crítica social" (Isunza, 2011, p. 57); en otras palabras, debilitar la formación de movimientos sociales.

Otro tipo de activación por políticas públicas tiene correlación con las "innovaciones democráticas" (Ibarra, 2002, p. 63) que la adopción de la democracia participativa ha conllevado en la región. Ese es el caso de la contraloría social de la ciudad de Caracas anexo a la llamada Dirección de Contraloría Social y Participación ciudadana creada en el 2007. Dicha contraloría captura a ciudadanos de las 32 parroquias en la que está conformada la ciudad a través de la figura del voluntariado (Álvarez, 2011, p. 188).

Estos voluntarios reciben por parte de la Alcaldía Metropolitana diversos programas de entrenamiento para la supervisión y vigilancia sobre la ejecución de los recursos y suministros en áreas como salud, educación, habitación o alimentación. A través de ella, la comunidad regula que las acciones cotidianas de los funcionarios sean cumplidas y con ello la estructura sobre la que se sostiene la política pública. Un segundo aspecto de esta contraloría son los consejos comunales. Estos consejos se forman "por miembros de la propia comunidad beneficiaria y su función es defender los intereses de la comunidad y los recursos otorgados por el gobierno de acuerdo a las políticas públicas aprobadas" (Álvarez, 2011, p. 189).

Tanto las contralorías sociales como los consejos comunales son ejemplos de las nuevas prácticas participativas que se han estructurando en el marco de la democracia participativa que el gobierno del Presidente Hugo Chávez ha implementado en Venezuela desde su llegada al poder. Estos mecanismos de participación ciudadana amplían la incidencia de la ciudadanía no solo en la formulación sino en un detallado seguimiento de su ejecución por parte de los funcionarios.

Esta proximidad entre gobierno y ciudadanía permite una interacción permanente y no periódica, entendida como "una salida, en clave democrática, a las insuficiencias que plantea en el contexto de la sociedad compleja y del conocimiento, la concepción elitista - competitiva de los procesos de gobierno" (Ibarra, 2002, p. 63). Es importante señalar que estas organizaciones sociales activadas de forma permanente para el control de los funcionarios y políticas del régimen, pueden en el marco de la polarización política y control de la movilización partidista por parte del gobierno, perder su capacidad de autonomía, vigilancia y transparencia. Al perder esta capacidad, los dispositivos de accountability social quedarían sin capacidad de sanción y denuncia, hecho que desvirtúa los principios y efectividad en los que se operacionaliza esta forma de control.

En los dos casos expuestos, la activación del accountability producida por políticas públicas no sería factible sin procesos de ciudadanía activa y capacidad organizativa de la sociedad, capaz 
de generar innovaciones democráticas importantes bajo el modelo de democracias participativas. Así, diversos mecanismos de accountability social, horizontal y administrativo se encuentran en todo el proceso de construcción e implementación de la política que favorecen "prácticas de control social ex -ante que a su vez, eventualmente pueden favorecer el control ex -post" (Cunill, 2002, p. 208). La experiencia de los presupuestos participativos de Porto Alegre y las contralorías sociales de Caracas evidencian que no solo "tienen capacidad de impacto político y operan en un contexto complejo de redes de política pública, sino que se van conformando como redes de acción colectiva crítica" (Ibarra, 2002, pp. 64 y 68).

2.1.3 Activación producida por efectos de movilización. Si bien la movilización social ha sido un recurso recurrente por parte de la ciudadanía para ser escuchados por parte de los gobernantes, en los últimos años las actuaciones y repertorios de acción usados por parte de los movimientos han transitado como afirma (Habermas 1981) de áreas de reproducción material canalizadas en partidos u organizaciones, a áreas de reproducción cultural, integración social y sociabilización. En ese sentido, las movilizaciones sociales actuales pueden ser clasificadas dentro de lo que se conoce como nuevos movimientos sociales (NMS). Estos movimientos evidencian la tensión entre el individuo y el Estado; donde se da importancia a las identidades y objetivos resultantes de diversas formas de asociacionismo y activismo colectivo con carácter movilizador (Melucci, 1985). En los NMS lo que importa es la movilización de la sociedad y no la toma del poder político.

A partir de esta última premisa, aquí se especifican aquellas realidades en las que las movilizaciones fueron el dispositivo fundamental que permitió la operacionalización de mecanismos de control y vigilancia. La activación por efectos de movilización puede contener dos subtipos el primero se denomina movilizaciones coyunturales. En ella, las movilizaciones son de cortísima duración y localizadas. Son accionadas por casos graves de corrupción o irrespeto a la normatividad que debe tener la actividad gubernamental. En ese sentido, al igual que la activación por escándalo político se necesita de los medios de comunicación para consolidarse como un actor desafiante.

El segundo subtipo se califica como movilizaciones sostenidas. En este caso la movilización es de larga duración y estructurada a través de organizaciones institucionalizadas que tienen líderes con experiencia gubernamental, conformada por miembros con alta capacitación y generadores de información y opinión. Se centran en temas como medio ambiente, seguridad, derechos humanos, lucha contra la inequidad, mujeres o desarrollo social. La movilización puede darse con cierta periodicidad o en momentos de oportunidad política específica pero capaz de mantenerse como una estructura de reserva. Es decir, "se interesan más en la incidencia de la planeación y la gestión desde una perspectiva de derechos que por acciones de control específico" (Hevia, 2002, p. 130).

Usando repertorios de acción colectiva tradicional y nueva en sus movilizaciones, las organizaciones sociales logran activar mecanismos de control activando respuestas legales del gobierno. 
En ese sentido, la presencia más que la extensión es lo que justifica la legitimidad de sus demandas (Smulovitz et al., 2002, p. 39). Sin embargo, la eficacia de este tipo de activación puede ser mayor cuando "la movilización social interactúa con mecanismos legales que activan acciones que obligan a las instituciones del Estado a considerar problemas que en su momento fueron dejados de lado" (Smulovitz et al., 2002, p. 40).

Un ejemplo del primer subtipo se presentó durante el primer semestre de 2011 en la ciudad de Bucaramanga, cuarta ciudad en importancia de Colombia. La multinacional peruano canadiense Greystar Resources, se encontraba tramitando ante los Ministerios de Minas y Medio Ambiente la licencia de explotación minera a cielo abierto en el Páramo de Santurban que abastece de agua a la ciudad y los municipios aledaños. Mientras la empresa realizaba el lobby para su aprobación, diversas organizaciones medio ambientales, comunitarias, sindicatos, partidos políticos regionales y gremios como Fenalco ${ }^{3}$ se organizaron en torno a la defensa del Páramo y en contra de la multinacional alegando elevados costos medioambientales imposibles de reparar que ya habían llevado a la Corporación para la Defensa de Bucaramanga una multa por los daños al ecosistema durante la fase de exploración (El Espectador, 18 de Enero de 2011).

En cuestión de días, los colectivos sociales de la ciudad se estructuraron de forma multiorganizativa y con una rápida capacidad de conectividad (Ibarra, 2002. pp. 68 y 69) que derivó en la convocatoria del 25 de febrero de 2011. Con una masiva movilización en la ciudad y en otras partes del país (Notiagen, 25 de febrero de 2011) y usando repertorios de acción tradicionales (marcha), novedosos (performances) y la recolección de firmas para llevar a cabo uso de acciones legales, las organizaciones sociales lograron dilatar el proceso de aprobación por parte de las instancias gubernamentales y la revisión del código minero existente por parte del legislativo colombiano.

Paralelo a ello, diversos medios de prensa escrita, televisiva y radial se involucraron en el proceso investigando las conveniencias de la explotación y evidenciando vacíos en la legislación minera colombiana. Uno de los efectos de la movilización del 25 de febrero fue la formación de una audiencia pública el 4 de marzo de 2011 a donde asistieron organismos de control como la Procuraduría, la Contraloría, los Ministerios, la Alcaldía, el Gobierno departamental y las organizaciones sociales de la ciudad.

El 17 de marzo de 2011 después de tres meses de haberse activado el accountability a través de una movilización coyuntural (la aprobación de la licencia ambiental), la multinacional minera decidió revocar la solicitud para explotar oro en el Páramo alegando que no existían

3. FENALCO o la Federación Nacional de Comerciantes, es uno de los gremios nacionales más antiguos con representación regional a lo largo del país. 
las condiciones para llevar a cabo el proyecto. Dos ejemplos de movilización sostenida se encuentran en México con la Alianza Cívica Nacional y en Colombia con la Misión de Observación electoral (MOE). Las dos organizaciones tienen la capacidad de "apelar a derechos y principios presionando el sistema político en un espacio público de confrontación" (Olvera, 2002, p. 221) que se centró en la vigilancia de todo el proceso del ciclo electoral.

México se encontraba durante la década de los noventa en un complejo proceso de debilitamiento del modelo político que se había instaurado después de la revolución de 1917. Bajo el gobierno del Partido Revolucionario Institucional (PRI) de Carlos Salinas de Gortari, múltiples actos de corrupción política, relación de políticos con los carteles de la droga y el desgaste de más de setenta años en el poder desataron una serie de luchas internas entre los diversos caciques políticos por la sucesión. Luego de ser elegido Luis Donaldo Colosio el 28 de noviembre de 1993 como el candidato por el PRI, pronuncia el 6 de marzo de 1994 un famoso discurso en el que rompe con Salinas y el modelo neoliberal que su gobierno había implantado. El 23 de marzo Colosio es asesinado y se desata una grave crisis política e institucional que golpea de forma importante la legitimidad del sistema político y del proceso electoral presidencial.

En este contexto y a partir de un pacto temporal establecido el 28 de abril de 1994, organizaciones sociales, ciudadanas, organizaciones no gubernamentales y centros de pensamiento prodemocrático vieron necesario crear una plataforma organizacional de la sociedad civil conocida como Alianza Cívica ${ }^{4}$. Esta organización se encargaría de vigilar la transparencia del proceso electoral y las instituciones. Combinando diversas metodologías de trabajo, la Alianza Cívica realizó un monitoreo detallado de las elecciones, lo cual incluyó observación en la elección de los candidatos y su trayectoria pública, incidencia de los partidos en la cobertura de los medios de comunicación nacionales y estatales, seguimiento de la normativa de financiación y formulación de la campaña electoral, revisión del padrón y vigilancia a los funcionarios del Instituto Federal Electoral durante el conteo y transmisión de los resultados.

Paralelo a estas actividades de tipo vigilante, la Alianza Cívica produjo diversos proyectos de tipo pedagógico como fue el programa "Ponte Vivo" a través del cual 4.500 observadores fueron capacitados en todos los aspectos del proceso electoral y enviados a regiones críticas en términos de seguridad, al tiempo que se coordinó la visita de observadores internacionales para la jornada electoral del 21 de agosto de 1994, que dio como ganador a Ernesto Zedillo. A partir de esta experiencia, la plataforma ha venido institucionalizando su práctica a través de los ejes participación ciudadana y vigilancia de procesos políticos, seguridad ciudadana y transparencia

4. La Alianza Cívica fue integrada por la Organización Movimiento Ciudadano por la Democracia, la Academia Mexicana de Derechos humanos, el Acuerdo por la Democracia, el Instituto Superior de la Cultura democrática, la Asamblea por el Sufragio efectivo y la Fundación Arturo Rosenblueth. 
y rendición de cuentas. Esto les ha permitido extender su presencia a lo largo de la mayoría de ciudades y municipios de México y mantenerse como una red organizativa estructurada y activa, capaz de movilizarse sostenidamente.

Con el objetivo de garantizar la transparencia de las elecciones, la Misión de Observación Electoral se conformó gracias al trabajo conjunto de diversas organizaciones locales y regionales preocupadas por los importantes niveles de fraude, coerción y presencia de actores armados ilegales en los procesos electorales en el 2002. Su primera vigilancia se llevó a cabo para las elecciones legislativas y presidenciales del 2006. En su carta de principios, la MOE considera que "este ejercicio de control ciudadano a los procesos electorales en todas sus etapas surgió en el seno de la confluencia por la democracia y contra la guerra, devolviendo la política a los ciudadanos y propiciando debates transparentes sobre la cosa pública" (Carta de Principios, MOE, 2006).

El trabajo de esta organización ha venido consolidándose de forma importante durante los últimos años gracias a seis áreas de trabajo en las que se estructura su labor, observatorio político de la democracia, monitoreo a medios de comunicación sobre la agenda pública de las autoridades, encuesta sobre temas de agenda electoral en Colombia, información, formación y debate sobre los temas de la agenda política, observación electoral a dignatarios del estado y observación nacional electoral. La diversidad de su trabajo, seriedad de sus observaciones e investigaciones y la creación de metodologías como los mapas de riesgo electoral, han permitido a la MOE convertirse en un actor fundamental de legitimación de los procesos electorales a través de diversos recursos institucionales y no institucionales que permite a esta plataforma movilizarse sostenidamente dentro del proceso político colombiano, lograr efectivos resultados de accountability y "generar mecanismos de incidencia política en instancias formales de participación" (Hevia, 2011, p. 131).

En los casos anteriores, la activación del accountability producida por efectos de movilización es posible gracias a organizaciones sociales con mayor nivel de institucionalización, capacidad organizativa y uso de recursos que les permite mantener vigilancia y control político de forma constante. De otra parte, el uso de movilizaciones coyunturales o sostenidas por parte de la ciudadanía nos muestra un mayor empoderamiento de la sociedad civil, acelerando mecanismos de control horizontal e incidir de forma importante en el accountability vertical.

Así, los mecanismos de accountability permiten la profundizar y radicalizar la democracia, que aspira no solo a mejorar la gobernanza y la prestación de servicios públicos, sino que busca disputar espacios y procedimiento propios de la democracia liberal representativa como sistema privilegiado de toma de decisiones y de relaciones entre el Estado y la sociedad" (Dagnino, Olvera \& Panfichi, 2007, p. 13). Por último, la operacionalización de diversos casos de 
accountability social en Latinoamérica evidencia una mayor capacidad de las instituciones democráticas para responder a las demandas de los colectivos sociales. La relación entre accountability social y calidad de la democracia se analizará en el siguiente apartado.

\section{ACCOUNTABILITY SOCIAL Y SU INCIDENCIA EN LA CALIDAD DE LA DEMOCRACIA}

Con la llegada de la democracia en la región durante la década de los ochenta y noventa, los diseños constitucionales que se instituyeron privilegiaron los aspectos político - institucionales del sistema político (Cuello, 2007, p. 34), dando importancia a las dimensiones procedimentales de la democracia. Sin embargo, estas no son suficientes frente "a los nuevos dominios a regular en las sociedades democráticas como son estado, mercado y sociedad civil" (Melo, 2011, p. 127). Este último dominio y su relación sobre la forma en que controla y funcionan sus mecanismos, ha tenido una menor atención en el debate académico frente a los numerosos estudios de accountability vertical y horizontal en correlación con la calidad de la democracia. Por ello, mediciones donde se incluya el accountability social puede arrojar explicaciones complementarias y evaluar la calidad de la misma.

Aunque existen diversas formas de medición de la democracia tanto de tipo cualitativo como cuantitativo, Freedom House, Polity IV, DataGob, Transparencia Internacional o Latinobarómetro han usado indicadores con los cuales han medido con consistencia este concepto en la región. Para hacer una medición del accountability social se propone el uso de tres indicadores. El primero, recogido por el Latinobarómetro, evalúa los momentos en que la comunidad se articula en temas que lo afecten de forma colectiva. Se espera que a un mayor activismo mayor capacidad de ejercer control político. El segundo, de Freedom House, es la garantía de libertad de prensa, elemento necesario para que el accountability social pueda tener mayor efectividad. El último indicador de Transparencia Internacional, es el de percepción de nivel de corrupción, "ligado a la eficacia de las instituciones estatales de control" (Barreda, 2011, p. 274).

\subsection{INDICADORES DE MOVILIZACIÓN}

La información para este indicador fue tomado de la base de datos del Latinobarómetro. Se utilizó la pregunta (A 50005), ¿Qué es más efectivo para influir en cambiar las cosas?, analizando el porcentaje por país de personas que decide participar en movimientos de protestas y exigir los cambios directamente (Tabla No 1). La segunda pregunta usada fue la pregunta (A 50102_MDI), ¿Qué conlleva ser buen ciudadano?, donde se muestra solamente la información referente a participación en organizaciones sociales (Tabla No. 2). En las dos tablas se muestra la relación por países y años. Se debe resaltar que para la tabla No. 1 el Latinobarómetro realizó esta pregunta solo en los años 2008 y 2009. Para la tabla No. 2, los años estudiados fueron 2008, 2009 y 2010. Cuba no se incluye en ninguna medición. 
Tabla No. 1. Participación en movimientos de protestas y exigir los cambios directamente

\begin{tabular}{|c|c|c|c|}
\hline País Años de Medición & 2008 & 2009 & Promedio \\
\hline Argentina & $13.8 \%$ & $10.4 \%$ & $12.1 \%$ \\
\hline Brasil & $23.1 \%$ & $27.1 \%$ & $25.1 \%$ \\
\hline Bolivia & $19.4 \%$ & $13.8 \%$ & $16.6 \%$ \\
\hline Chile & $7.7 \%$ & $9.3 \%$ & $8.5 \%$ \\
\hline Colombia & $14.0 \%$ & $17.9 \%$ & $15.9 \%$ \\
\hline Costa Rica & $18.9 \%$ & $11.0 \%$ & $14.9 \%$ \\
\hline Ecuador & $24.1 \%$ & $22.7 \%$ & $23.4 \%$ \\
\hline El Salvador & $19.1 \%$ & $9.4 \%$ & $14.2 \%$ \\
\hline Guatemala & $27.9 \%$ & $29.0 \%$ & $28.4 \%$ \\
\hline Honduras & $21.5 \%$ & $14.9 \%$ & $18.2 \%$ \\
\hline México & $14.9 \%$ & $16.2 \%$ & $15.5 \%$ \\
\hline Nicaragua & $11.9 \%$ & $9.0 \%$ & $10.4 \%$ \\
\hline Panamá & $14.9 \%$ & $12,1 \%$ & $13.5 \%$ \\
\hline Paraguay & $17.8 \%$ & $17.3 \%$ & $17.5 \%$ \\
\hline Perú & $23.2 \%$ & $21.7 \%$ & $22.4 \%$ \\
\hline República Dominicana & $13.6 \%$ & $18.5 \%$ & $16.0 \%$ \\
\hline Uruguay & $10.4 \%$ & $4.8 \%$ & $7.6 \%$ \\
\hline Venezuela & $9.2 \%$ & $9.7 \%$ & $9.45 \%$ \\
\hline Promedio General Latinoamérica & $16.9 \%$ & $15.2 \%$ & $16.0 \%$ \\
\hline
\end{tabular}

Fuente: Elaboración propia a partir de los datos del Latinobarómetro.

Entre 2008 y 2009 aumentó la participación política a través de protestas en Brasil, Chile, Colombia, Guatemala, México, República Dominicana y Venezuela. Decreció en Perú, Nicaragua, Honduras, El Salvador, Ecuador, Costa Rica, Bolivia y Argentina, siendo el caso de El Salvador el más significativo. Los casos de mayor estabilidad Paraguay y Panamá. La extensión de la participación con acciones no contenciosas puede explicarse en correlación con el aumento de percepción de la corrupción que activa una serie de movilizaciones y formas organizativas más de tipo local que nacional, utilizando para ello mecanismos de control institucional y administrativo con el objetivo de activar sanciones judiciales. En el caso de Guatemala y 
República Dominicana con prácticas autoritarias aun presentes en su sistema político, el aumento leve en este tipo de participación evidencia debilidad de los partidos políticos tradicionales por hacer los cambios, dejando a los movimientos ciudadanos y sociales mayor capacidad de maniobra especialmente en temas de derechos humanos que se activaron bajo el proceso electoral del 2008.

El escaso aumento en Venezuela de la participación puede responder más a acciones colectivas a los que acude la oposición para solicitar cambios respecto a las decisiones que el gobierno del Presidente Hugo Chávez ha tenido en temas como medios de comunicación, libertad de prensa, propiedad privada, control de divisas o participación política. En cuanto a la disminución de protestas en la mayoría de países relacionados las caídas no son significativas. Se destaca el caso de El Salvador, con una caída importante en pleno proceso de cambio presidencial al gobierno del FMLN lo que nos habla del uso de canales más institucionales por parte de la ciudadanía.

Otro caso es el de Uruguay, donde los procesos de Debate y Diálogos Ciudadanos sobre políticas públicas del gobierno de Tabaré Vásquez, puede evidenciarnos una mejora en la acción gubernamental replicada en una mayor institucionalización y eficiencia de los mecanismos de accountabilty horizontales y electorales. Atención especial merece el caso de Nicaragua. La disminución de la protesta puede deberse a un control mayor y en algunos casos coercitivos por parte del partido gobernante de Daniel Ortega el FSLN. En Panamá y Paraguay no vemos cambios significativos debido a políticas de mayor impacto e inclusión ciudadana como fue el principio de gobierno de Martín Torrijos y Fernando Lugo.

Finalmente, en este indicador encontramos tendencias mixtas respecto a la protestas como forma de exigir los cambios. Aunque podemos ver el uso sostenido de esta forma de acción colectiva, los números no nos dan cifras ascendentes en toda la región; lo cual puede visibilizar mejoras en las formas de control institucional y uso de formas de política no convencional en casos específicos de denuncia o vigilancia como busca el accountability social (ver tabla 2).

La participación en organizaciones sociales aumentó en Argentina, Chile, Nicaragua, Uruguay y Paraguay y disminuyó pero no de forma significativa en Bolivia, Costa Rica, Ecuador, Guatemala y Perú. En el resto de casos la participación no tiene oscilaciones significativas. En la mayoría de países la participación en organizaciones sociales sigue siendo un asunto primordial para la ciudadanía. Un punto importante es la diversidad de organizaciones sociales que cubren temáticas como protección y defensa de los derechos humanos, medio ambiente, feminismo, problemas agrarios o mejoramiento de servicios públicos. Se debe resaltar el aumento de organizaciones sociales en Chile y Uruguay lo que responde más a formas organizativas institucionalizadas y activadas en la modalidad de accountability social producida por políticas públicas. En este tipo de activación y en la de movilizaciones es donde las organizaciones sociales tienen capacidad de incidencia. 
Tabla No 2. Participación en organizaciones sociales

\begin{tabular}{|l|r|r|r|c|}
\hline \multirow{2}{*}{\multicolumn{1}{|c|}{ País }} & \multicolumn{4}{|c|}{ Años de Medición } \\
\cline { 2 - 5 } & $\mathbf{2 0 0 8}$ & $\mathbf{2 0 0 9}$ & $\mathbf{2 0 1 0}$ & Promedio \\
\hline Argentina & $5.8 \%$ & $4.5 \%$ & $5.6 \%$ & $5.30 \%$ \\
Brasil & $5.8 \%$ & $5.4 \%$ & $5.3 \%$ & $5.50 \%$ \\
Bolivia & $4.6 \%$ & $4.6 \%$ & $4.2 \%$ & $4.46 \%$ \\
Chile & $8.4 \%$ & $9.0 \%$ & $9.2 \%$ & $8.86 \%$ \\
Colombia & $5.1 \%$ & $4.5 \%$ & $4.9 \%$ & $4.83 \%$ \\
Costa Rica & $4.7 \%$ & $6.6 \%$ & $4.8 \%$ & $5.36 \%$ \\
\hline Ecuador & $9.3 \%$ & $6.5 \%$ & $4.4 \%$ & $6.73 \%$ \\
El Salvador & $10.4 \%$ & $6.1 \%$ & $6.9 \%$ & $7.80 \%$ \\
Guatemala & $5.8 \%$ & $8.4 \%$ & $6.7 \%$ & $6.96 \%$ \\
Honduras & $6.6 \%$ & $3.2 \%$ & $2.9 \%$ & $4.23 \%$ \\
\hline México & $4.5 \%$ & $3.9 \%$ & $3.9 \%$ & $4.10 \%$ \\
\hline Nicaragua & $4.4 \%$ & $3.3 \%$ & $4.8 \%$ & $4.16 \%$ \\
\hline Panamá & $3.1 \%$ & $3.7 \%$ & $3.8 \%$ & $3.53 \%$ \\
\hline Paraguay & $5.1 \%$ & $4.8 \%$ & $7.5 \%$ & $5.80 \%$ \\
\hline Perú & $4.8 \%$ & $3.8 \%$ & $3.1 \%$ & $3.90 \%$ \\
\hline República Dominicana & $5.6 \%$ & $4.6 \%$ & $4.3 \%$ & $4.83 \%$ \\
\hline Uruguay & $3.6 \%$ & $4.2 \%$ & $4.6 \%$ & $4.13 \%$ \\
\hline Venezuela & $6.6 \%$ & $5.6 \%$ & $5.6 \%$ & $5.93 \%$ \\
\hline Promedio General & $5.78 \%$ & $5.15 \%$ & $5.13 \%$ & $5.35 \%$ \\
\hline Latinoamérica & & & & \\
\hline
\end{tabular}

Fuente: Elaboración propia a partir de los datos del Latinobarómetro.

Por lo tanto, la participación de la sociedad en múltiples organizaciones sociales no busca competir con el voto, sino como afirma (Avritzer, 2002) vincular nuevos espacios, grupos y redes sociales a las estructuras institucionales del sistema político de forma que encuentren representación. Situación que replica en una calidad democrática mayor, en temas como desarrollo económico, justicia o igualdad. 


\subsection{INDICADOR DE LIBERTAD DE PRENSA}

La información para este indicador fue tomado de la base de datos de Freedom House sobre libertad de prensa. En ella se clasifican los países en Libres (L), que va en un porcentaje de 0 $30 \%$, Parcialmente Libres (PL), en porcentajes que va de $31-60 \%$ y No Libres (NL), que va de $61-100 \%$. En esta muestra la relación es por países y años. Los años de estudio son 2008 a 2011. Cuba se incluye en esta medición.

Tabla 3. Garantía Libertad de Prensa

\begin{tabular}{|l|c|c|c|c|c|}
\hline \multirow{2}{*}{\multicolumn{1}{|c|}{ Países }} & \multicolumn{5}{c|}{ Años de Medición } \\
\cline { 2 - 6 } & $\mathbf{2 0 0 8}$ & $\mathbf{2 0 0 9}$ & $\mathbf{2 0 1 0}$ & $\mathbf{2 0 1 1}$ & Promedio país \\
\hline Argentina & 47 & 49 & 49 & 51 & 49.0 \\
Brasil & 42 & 42 & 43 & 44 & 42.7 \\
Bolivia & 39 & 42 & 43 & 46 & 42.5 \\
Chile & 30 & 29 & 30 & 29 & 29.5 \\
Colombia & 59 & 59 & 60 & 56 & 58.5 \\
Costa Rica & 19 & 19 & 19 & 18 & 18.7 \\
Cuba & 94 & 94 & 93 & 92 & 93.2 \\
Ecuador & 41 & 44 & 47 & 52 & 46.0 \\
El Salvador & 42 & 42 & 43 & 42 & 42.2 \\
Guatemala & 58 & 60 & 60 & 59 & 59.2 \\
Honduras & 51 & 52 & 59 & 61 & 55.7 \\
México & 51 & 55 & 60 & 62 & 57.0 \\
Nicaragua & 43 & 45 & 47 & 47 & 45.5 \\
Panamá & 44 & 44 & 44 & 44 & 44.0 \\
Paraguay & 60 & 59 & 59 & 60 & 59.5 \\
Perú & 44 & 44 & 44 & 43 & 43.7 \\
República Dominicana & 40 & 39 & 40 & 41 & 40.0 \\
Uruguay & 26 & 25 & 25 & 26 & 25.5 \\
Venezuela & 73 & 75 & 76 & 76 & 75.0 \\
Promedio General & & & & & \\
Latinoamérica & 47.5 & 48.3 & 49.5 & 49.9 & 45.8 \\
\hline
\end{tabular}

Fuente: Elaboración propia a partir de la información de Freedom House. 
Unos medios de comunicación que informen libremente, que no estén cooptados por fuerzas económicas y políticas y que puedan ejercer su oficio sin ningún tipo de coerción y violencia, son condiciones importantes para garantizar la libertad de prensa. El ejercicio del accountability social requiere este tipo de condiciones para una mayor efectividad. Los resultados de la región de 2008 a 2011 presentan variaciones. Chile, Costa Rica y Uruguay mantienen índices altos de libertad de prensa, que se relacionan con una ciudadanía mejor informada y con niveles importantes de participación que incluye organizaciones sociales. Se destaca el caso chileno con una libertad de prensa amplia que incluyó el acceso a redes sociales, definitivas en el proceso de movilización del Movimiento Estudiantil chileno por la reforma a la política pública educativa. El caso de Uruguay también se destaca por su pluralismo informativo y garantía por parte de los gobiernos que permite una interacción crítica por parte de la ciudadanía sobre los avances en el proceso de formulación e implementación de las políticas públicas.

Los indicadores de Venezuela, Cuba, México y Guatemala preocupan en la medida en que son considerados entre parcialmente libres a no libres, es decir, el ejercicio de libertad de información ha sido objeto de decisiones gubernamentales que han limitado su ejercicio. En el caso de Venezuela o Nicaragua, el enfrentamiento entre el Presidente y un numeroso grupo de medios de comunicación, han debilitado seriamente el ejercicio periodístico y la independencia informativa que debe garantizarse en una democracia. En ese sentido, los recursos informativos se encuentran fuertemente controlados por el partido de gobierno así como muchas de las organizaciones sociales, situación que dificulta el ejercicio de un accountability social efectivo e independiente.

El sostenido deterioro de la libertad de prensa en Ecuador y Argentina se explica por un mayor control informativo por parte del gobierno de Rafael Correa y Cristina Fernández de Kirchner, quienes han acusado a los medios de comunicación de sus países de distorsionar la información, perseguir a sus funcionarios y favorecer a la oposición. Usando acciones judiciales, el Presidente de Ecuador ha denunciado y pedido expulsión de periodistas y llevado juicios contra los directores del Diario La Hora y demandas contra el Diario el Universo. En el caso argentino, la Presidenta Fernández en octubre de 2010, habló de "nacionalizar los medios de comunicación" (Libertad digital, 20 de octubre de 2010) y siguió su línea de confrontación contra el Diario el Clarín. Esta tensión ha dificultado la capacidad de denuncia contra acciones de funcionarios y decisiones gubernamentales, por parte de la prensa ecuatoriana y argentina.

En el caso de México y Guatemala, la violencia de los carteles de la droga y policial en su lucha contra las fuerzas de seguridad estatales, ha sido un actor significativo en el deterioro de la libertad de prensa, situación que ha empujado a la ciudadanía a buscar a través de movilizaciones ciudadanas la denuncia de los graves hechos y atentados que los periodistas y medios de comunicación han sufrido. De otro lado, Colombia, Perú y El Salvador han mostrado avances 
significativos en el libre ejercicio de la prensa, aunque se siguen clasificando como países parcialmente libres. En el caso colombiano, el cambio de gobierno ha hecho énfasis en un discurso más respetuoso y de acercamiento con los medios de comunicación y actores sociales, brindando incentivos institucionales y activando mecanismos de control horizontal (investigaciones y denuncias por actos de corrupción) que no solo han debilitado la polarización ideológica presente en el gobierno anterior, sino una percepción de mayor confianza en las instituciones gubernamentales.

Así, la libertad de prensa es un elemento fundamental para que los mecanismos de accountability social puedan activarse y ser efectivos. Aunque en Latinoamérica la censura, coerción y control a la información por parte de sectores políticos y grupos violentos se sigue presentando, la tendencia general de la región es fortalecer los elementos que Dahl considera integrales para el fortalecimiento y calidad de la democracia. Esto significa que debe existir un mayor nivel e igualdad de recursos informativos para la ciudadanía.

\subsection{INDICADOR PERCEPCIÓN DEL NIVEL DE CORRUPCIÓN}

La información para este indicador fue tomado de la base de datos de Transparency International. En ella los países cerca a 10 se clasifican como de baja percepción de corrupción los que están cerca a 0 son percibidos como de alta corrupción. En esta muestra la relación es por países y años. Los años de estudio va de 2008 a 2011. Cuba se incluye en esta medición (ver tabla 4).

La corrupción sigue siendo uno de los problemas más graves que enfrenta y dificulta la implementación de una democracia más sustantiva en la región. Para la ciudadanía y diversos analistas, "la lucha contra la corrupción se ha convertido en uno de los componentes obligados en toda agenda nacional de desarrollo, formando parte de las tareas de fortalecimiento y mejora de las instituciones" (Alonso, 2012, p. 42). Sin embargo, esta lucha también visibiliza grados deficientes respecto a la forma y funcionamiento de los mecanismos de accountabilty horizontal. Las conclusiones de los resultados desde 2008 a 2011 muestran resultados sostenidos respecto a una alta percepción de corrupción no solo pública sino también del ámbito privado.

Chile, Costa Rica y Uruguay siguen manteniendo índices positivos en cuanto a transparencia y bajos niveles de corrupción. Parte de este éxito se debe a una efectividad de los mecanismos institucionales combinado con una ciudadanía activa y participativa así como unos medios libres y pluralistas capaces de ejercer control a las decisiones y planes gubernamentales. A ello se suma un nivel de desarrollo e igualdad de recursos económicos, políticos, cognitivos e informativos que permite mayor efectividad en su gestión y control político e institucional. En contraste, Ecuador, Venezuela y Paraguay muestran los indicadores más bajos de percepción de la corrupción. En el caso venezolano, la riqueza de los ingresos petroleros junto con un 
Tabla 4. Percepción nivel de corrupción

\begin{tabular}{|l|c|c|c|c|c|}
\hline \multirow{2}{*}{\multicolumn{1}{|c|}{ Países }} & \multicolumn{5}{|c|}{ Años de Medición } \\
\cline { 2 - 6 } & $\mathbf{2 0 0 8}$ & $\mathbf{2 0 0 9}$ & $\mathbf{2 0 1 0}$ & $\mathbf{2 0 1 1}$ & Promedio país \\
\hline Argentina & $2.9 \%$ & $2.9 \%$ & $2.9 \%$ & $3.0 \%$ & $2.92 \%$ \\
Brasil & $3.5 \%$ & $3.7 \%$ & $3.7 \%$ & $3.8 \%$ & $3.67 \%$ \\
Bolivia & $3.0 \%$ & $2.7 \%$ & $2.8 \%$ & $2.8 \%$ & $2.82 \%$ \\
Chile & $6.9 \%$ & $6.7 \%$ & $7.2 \%$ & $7.2 \%$ & $7.00 \%$ \\
Colombia & $3.8 \%$ & $3.7 \%$ & $3.5 \%$ & $3.4 \%$ & $3.60 \%$ \\
Costa Rica & $5.1 \%$ & $5.3 \%$ & $5.3 \%$ & $4.8 \%$ & $5.12 \%$ \\
Cuba & $4.3 \%$ & $4.4 \%$ & $3.7 \%$ & $4.2 \%$ & $4.15 \%$ \\
Ecuador & $2.0 \%$ & $2.2 \%$ & $2.5 \%$ & $2.7 \%$ & $2.35 \%$ \\
El Salvador & $3.9 \%$ & $3.4 \%$ & $3.6 \%$ & $3.4 \%$ & $3.57 \%$ \\
Guatemala & $3.1 \%$ & $3.4 \%$ & $3.2 \%$ & $2.7 \%$ & $3.10 \%$ \\
\hline Honduras & $2.6 \%$ & $2.5 \%$ & $2.4 \%$ & $2.6 \%$ & $2.52 \%$ \\
México & $3.6 \%$ & $3.3 \%$ & $3.1 \%$ & $3.0 \%$ & $3.25 \%$ \\
\hline Nicaragua & $2.5 \%$ & $2.5 \%$ & $2.5 \%$ & $2.5 \%$ & $2.50 \%$ \\
\hline Panamá & $3.4 \%$ & $3.4 \%$ & $3.6 \%$ & $3.3 \%$ & $3.42 \%$ \\
\hline Paraguay & $2.4 \%$ & $2.1 \%$ & $2.2 \%$ & $2.2 \%$ & $2.22 \%$ \\
Perú & $3.6 \%$ & $3.7 \%$ & $3.5 \%$ & $3.4 \%$ & $3.55 \%$ \\
\hline República Dominicana & $3.0 \%$ & $3.0 \%$ & $3.0 \%$ & $2.6 \%$ & $2.90 \%$ \\
Uruguay & $6.9 \%$ & $6.7 \%$ & $6.9 \%$ & $7.0 \%$ & $6.87 \%$ \\
\hline Venezuela & $1.9 \%$ & $1.9 \%$ & $2.0 \%$ & $1.9 \%$ & $1.92 \%$ \\
\hline Promedio General & $3.60 \%$ & $3.55 \%$ & $3.55 \%$ & $3.50 \%$ & $3.55 \%$ \\
\hline
\end{tabular}

Fuente: Elaboración propia a partir de la información de Transparencia Internacional.

control férreo por parte del gobierno de los recursos económicos, políticos e institucionales a través de las misiones sociales y los programas de asistencia, han elevado la corrupción estatal. Esto conlleva a una mayor participación y creación de múltiples organizaciones sociales controlados y dirigidos por el gobierno que se activan no sólo en momentos electorales sino en el sostenimiento del régimen. 
En Paraguay el grado de corrupción ha aumentado entre el 2010 y el 2011. La presencia de prácticas autoritarias en las regiones rurales y la dificultad de ejercer reformas estructurales que mejoren la capacidad institucional del país, demuestran la ausencia o debilidad de los mecanismos de control horizontal. Esta debilidad se replica en una ciudadanía poco activa y participativa que se evidencia en la similitud de los resultados de sus indicadores. Esto tiene implicaciones para el accountability social, con serías dificultades para estructurarse. En contraste con la debilidad de los medios de comunicación paraguayos, la prensa en Ecuador a pesar de los controles y acciones gubernamentales, ha denunciado los actos de corrupción de funcionarios del gobierno de Rafael Correa, que los ha defendido usando procedimientos institucionales y acciones judiciales para demostrar la transparencia de su gobierno.

Los restantes países mantienen unos niveles de corrupción alto que varían poco en los años de estudio. Sin embargo, se debe destacar la presencia dentro de las denuncias que los medios de comunicación y sociedad civil han venido haciendo sobre niveles importantes de corrupción por parte de la empresa privada en áreas como la minería, área fundamental de crecimiento económico y desarrollo para la mayoría de los países latinoamericanos. La publicación misma de estos hechos y el encarcelamiento e inicio de procesos judiciales en muchos países, demuestran que el accountability social producido por efectos de movilización o políticas públicas, ha tenido algunos resultados efectivos de control y positivos en cuanto a la discusión sobre la calidad integral de la democracia.

\section{CONCLUSIONES}

La pertinencia de consolidar formas de control al ejercicio gubernamental, ha permitido la activación de una forma de control político llamado accountability social. En los últimos años, este se ha replicado a lo largo de la región fortaleciendo no sólo la participación política, sino una incidencia mayor de la sociedad civil en la vigilancia, decisiones y políticas de los funcionarios, activando otro tipo de controles institucionales que han venido fortaleciendo los indicadores en los que se inscribe la calidad de la democracia en la región.

En primer lugar, los procesos de democratización que vivió la región durante la década de los ochenta y noventa del siglo pasado, incluyeron en sus diseños constitucionales mecanismos de control y regulación de las acciones y procesos de decisión de sus gobiernos y funcionarios. Esto ha permitido la creación y fortalecimiento de diversas instituciones y dispositivos de accountability que junto con el crecimiento de diversas organizaciones sociales e iniciativas ciudadanas, han incidido en el fortalecimiento de la democracia y los indicadores en los que se mide su calidad.

En segundo lugar, el concepto de accountability está profundamente relacionado con la democracia representativa que requiere combinar un marco institucional de autorización del poder con uno orientado a asegurar la responsabilidad y receptividad de los actores involucrados. 
La construcción de este vínculo entre gobernantes y gobernados basado en la representación, requiere del establecimiento de confianza y autonomía. Por lo tanto, el accountability se estructura a través de dos dimensiones: el answerability y el enforcement. La primera se refiere a la obligación de los funcionarios y políticos de informar acerca sus decisiones y justificarlas públicamente. La segunda resalta la existencia entre la rendición de cuentas y la sanción, al entenderse como la capacidad de imponer castigos a aquellos funcionarios que hayan violado sus deberes o incumplido sus obligaciones.

La instrumentalización del accountabilty contiene un nivel legal y social que va intrincado en el proceso de ejercicio del poder, el cual se puede clasificar en varios tipos. El accountability legal, que busca que las acciones de los funcionarios estén enmarcadas en una estructura legal con mecanismos constitucionales o procedimientos administrativos que aseguren que los gobiernos respeten la ley y el debido proceso. El vertical, resultado de unas elecciones limpias e institucionalizadas a través de las cual los ciudadanos responsabilizan a los gobiernos de sus acciones. De otro lado, el accountabilty horizontal muestra la presencia y capacidad de las agencias del estado de emprender acciones sancionatorias, en relación con actos u omisiones de agentes o agencias del Estado que pueden ser calificadas como ilegales. Por último, se encuentra el accountability administrativo, que apunta a la necesidad de formar una burocracia profesional, con respeto al debido proceso, la ley y efectividad del sistema legal.

En tercer lugar, se ha venido consolidando dentro de los mecanismos de rendición de cuentas el accountability social considerado como un modo de control vertical de las autoridades políticas, basado en las acciones de organizaciones sociales y asociaciones ciudadanas que incluyen para su efectividad el uso de acciones mediáticas. A través de estos mecanismos, grupos de ciudadanos fiscalizan la gestión de la administración pública, denuncian actos de corrupción o presentan propuestas para la adopción de políticas públicas.

De esta forma, el accountability social retorna a los sistemas políticos el tema de la confianza, una especie de "institución invisible" que amplía la calidad de la legitimidad al añadir una dimensión moral y una sustancial. Además, le da un carácter temporal (se mantiene como un valor en el tiempo) y es un economizador institucional. Por lo tanto, la práctica del accountability social incide en todas las esferas del poder público, debido a la estrategia jurídica, movilizacional y mediática en la que se estructura.

En cuarto lugar, la sociedad civil latinoamericana ha estimulado una mayor actividad e interés en el diseño y organización del sistema político. En ella la ciudadanía y las instituciones intentan encuadrar dentro de las normas de responsabilidad y responsiveness que legitiman la representación e inciden dentro de las decisiones gubernamentales. En esa medida, diversos casos de accountability social se han presentado en países latinoamericanos a través de tres tipos de activación: la activación producida por escándalos políticos, políticas públicas y movilización. Así, estos tipos de activación del accountability social, permiten una profundización de la 
democracia que aspira no solo a mejorar la gobernanza, sino disputar espacios y procedimientos de la democracia liberal representativa como sistema de toma de decisiones y relaciones entre Estado y ciudadanía.

En quinto lugar, la operacionalización del accountability social evidencia una mayor capacidad de las instituciones democráticas en Latinoamérica para responder a las demandas de los colectivos sociales, frente a las nuevas potestades a regular como el estado, el mercado y la sociedad civil. En ese orden de ideas, la democracia es medible en países que tienen un mínimo grado de democratización como Latinoamérica, donde existen procedimientos que controlan la forma en que se accede al poder y se hace necesario determinar otros elementos como el desarrollo económico, la justicia social o la igualdad.

Por último, el accountability social puede convertirse en un indicador de calidad de la democracia a través de la medición de tres aspectos movilización, libertad de prensa y percepción de corrupción en los últimos años. Los resultados evidencian no solo mejoras en formas de control institucional sino en el uso de formas de acción política no convencional movilizaciones, protestas o marchas estructuradas en múltiples organizaciones sociales y mediáticas que no buscan competir con el voto, sino vincular nuevos espacios, grupos y redes sociales a las estructuras institucionales del sistema político, replicando en el fortalecimiento de los elementos que Dahl llama integrales para la calidad de la democracia.

\section{BIBLIOGRAFÍA}

\section{Libros}

- Ackerman, J. (2006). Estructura institucional para la rendición de cuentas: Lecciones internacionales y reformas futuras. México: Auditoria Superior de la Federación.

- $\quad$ Avritzer, L. (2002). Democracy and the Public Space in Latin American. Princeton: Princeton University Press.

- Dagnino, E., Olvera A. \& Panfichi. A. (2006). La Disputa por la Construcción Democrática en América Latina. México: CIESAS, Editorial Universidad Veracruzana.

- Jiménez. E. (2009). Reinterpretando la rendición de cuentas o accountability: diez propuestas para la mejora de la calidad democrática y la eficacia de las políticas públicas en España. Madrid: Fundación Alternativas.

- Manin, B. (1998). Los principios del Gobierno Representativo. Madrid: Editorial Alianza. 
- $\quad$ March, J. \& Olsen, J. (1995). Democratic Governance. New York: The Free Press.

- Przeworski, A. Stokes, S. \& Manin. B. (1999). Democracy, Accountability, and Representation. Cambridge: University Press.

- $\quad$ Putnam, R. (1993). Making democracy work. Princeton: University Press.

- $\quad$ Rosanvallon, P. (2007). La Contrademocracia, la Política en la era de la desconfianza. Buenos Aires: Editorial Manantial.

- $\quad$ Sartori, G. (2003). Video política. Medios, información, y democracias de sondeo. México: Instituto Tecnológico y de Estudios Superiores de Monterrey, Fondo de Cultura Económica.

- Smulovitz, C. \& Peruzzotti, E. (2002). Controlando la política: Ciudadanos, medios en las nuevas democracias latinoamericanas. Buenos Aires: Editorial Temas.

- $\quad$ Tarrow, S. (1998). El poder en movimiento. Madrid: Editorial Alianza.

- Touraine, A. (1981). The voice and the eye. An analysis of social movements. Cambridge: University Press.

\section{Capítulos de Libro}

- Álvarez, R. (2011). El caso de Caracas. En A. Hernández \& E. Arciniegas (Eds.). Experiencias de Accountability horizontal y social en América Latina (pp. 149-196). Bogotá: Editorial Universidad de los Andes.

- $\quad$ Avritzer, L. (2002). Modelos de formación de Estado y sociedad y su impacto en el accountability, comentarios sobre el caso brasileño. En C. Smulovitz, \& E. Peruzzotti (Eds.). Controlando la política: Ciudadanos, medios en las nuevas democracias latinoamericanas (p 139 - 168). Buenos Aires: Editorial Temas.

- $\quad$ Cunill, N. (2002). Nudos críticos de la accountability social. Extrayendo lecciones de su institucionalización en América Latina. En C. Smulovitz \& E. Peruzzotti (Eds.). Controlando la política: Ciudadanos, medios en las nuevas democracias latinoamericanas, (p 193- 217). Buenos Aires: Editorial Temas.

- Hernández, A. \& Arciniegas, E. (2011). Aproximación conceptual, el accountability desde una perspectiva comparada en América Latina: Estudios de caso. En A. Hernández \& E. Arciniegas (Eds.). Experiencias de Accountability horizontal y social en América Latina (pp. 21-48). Bogotá: Editorial Universidad de los Andes. 
- Hevia, F. (2011). El caso de México D.F. En A. Hernández \& E. Arciniegas (Eds.). Experiencias de Accountability horizontal y social en América Latina ( $p$ 95- 148). Bogotá: Editorial Universidad de los Andes.

- Ibarra, P. (2002). Redes de acción colectiva crítica e impactos políticos. En P. Ibarra, S. Martí \& R. Gomá (Eds.). Creadores de Democracia radical. Movimientos sociales y redes de políticas públicas (pp. 57-79). Barcelona: Editorial Icaria Política.

- Isunza. E. (2011). El caso de Sao Paulo. En A. Hernández \& E. Arciniegas (Eds.). Experiencias de Accountability horizontal y social en América Latina (p 49-94). Bogotá: Editorial Universidad de los Andes.

- Lynch, N. (2002). Los usos de los medios en el Perú de Fujimori. En C. Smulovitz. \& E. Peruzzotti (Eds.). Controlando la política: Ciudadanos, medios en las nuevas democracias latinoamericanas (pp. 263-288). Buenos Aires: Editorial Temas.

- O’Donnell, G. (1999). Horizontal accountability in New Democracies. En A. Schedler, L. Diamond \& M. Plattner (Eds).The self-Restraining State power and accountability in new democracies (pp. 29-53). London: Lynne Reinner Publishers.

- O’Donnell, G. (2002). Acerca de varias accountabilities y sus interrelaciones. En C. Smulovitz \& E. Peruzzotti (Eds.). Controlando la política: Ciudadanos, medios en las nuevas democracias latinoamericanas (pp. 87-102). Buenos Aires: Editorial Temas.

- Olvera, A. (2002). Accountability social en México: La experiencia de la Alianza Cívica. En C. Smulovitz \& E. Peruzzotti (Eds.). Controlando la política: Ciudadanos, medios en las nuevas democracias latinoamericanas (pp. 219-253). Buenos Aires: Editorial Temas.

- $\quad$ Peruzzotti, E. (2006). La política del accountability social en América Latina. En E. Isunza \& A. Olvera (Eds). Democratización, rendición de cuentas y sociedad civil: participación ciudadana y control social (pp. 245-264). México: Editorial Universidad Veracruzana.

- $\quad$ Schedler, A. (1999). Conceptualizing Accountability. En A. Schedler, L. Diamond, \& M. Plattner (Eds). The self-Restraining State power and accountability in new democracies (pp. 13-29). London: Lynne Reinner Publishers.

- Waisbord, S. (2002). Interpretando los escándalos. Análisis de su relación con los medios y la ciudadanía en la argentina contemporánea En C. Smulovitz \& E. Peruzzotti (Eds.). Controlando la política: Ciudadanos, medios en las nuevas democracias latinoamericanas. (pp. 289-325). Buenos Aires: Editorial Temas. 


\section{Artículos de Revista especializada}

- Alonso, J. (2012). Corrupción y calidad institucional en América Latina. Anuario Iberoamericano, sn, 42- 61.

- Barreda, M. (2011). La calidad de la democracia: un análisis comparado de América Latina. Política y Gobierno, XVIII (2), 265-295.

- Cuello, J. (2007). Democracia: institucionalización y accountability. Revista de la Facultad de Ciencias Jurídicas y sociales, 5, 33-47.

- $\quad$ Habermas, J. (1981). New Social Movements. Revista Telos, 49, 3-37.

- Levine, D. \& Molina, J. (2007). La calidad de la democracia en América Latina una visión comparada. Revista América Latina Hoy, 45, 17-46.

- Lipset, S. (1996). Repesando los requisitos sociales de la democracia. Revista Ágora, 5, 29-65.

- Melo, M. (2011). Accountability: diseño institucional y calidad de la democracia. Revista Latinoamericana de política comparada, 5, 125-154.

- Melucci A. (1985). The symbolic challenge of contemporany movements. Social Research, 19, 789-816.

- $\quad$ O'Donnell, G. (1998). Accountability Horizontal. Revista Ágora, IV, 8, 5-34.

- O'Donnell, G. (2001). La irrenunciabilidad del Estado de Dere-cho. Instituciones y Desarrollo, VIII (9), 43-82.

- O`Donnell, G. (2004). Accountabilty Horizontal: la institucionalización legal de la desconfianza política Revista española de Ciencia Política, 11, 11-31.

- Schedler, A. (2008). ¿Qué es la rendición de cuentas? Cuadernos de Transparencia, 3, 9-39.

- Weffort, F. (1992). ¿New Democracies, Which Democracies? Working Paper, 198, Washington: The Woodrow Wilson Center, Latin American Program. 


\section{Artículos en red}

- $\quad$ Barreda, M. (2010). Accountability y calidad de la democracia en América Latina: un análisis comparado Ponencia Asociación de Estudios Latinoamericanos LASA. Recuperado 10 de agosto de 2012, de: lasa.international.pitt.edu/members/congresspapers/.../1293.pdf

- Pérez, M. (2003). El Presupuesto Participativo de Porto Alegre como herramienta de democracia. Un análisis crítico: Lo que sabemos y lo que nos falta por saber. Ponencia II Jornadas de Sociología Política. Recuperado el 14 de agosto de 2012, de: http:// www.fes-web.org/sociopolitica/documentos/2jornadas/martinez.pdf

- Peruzzotti, E. (2008). Marco conceptual de la Rendición de Cuentas. Reunión Técnica de la Comisión de Rendición de Cuentas de la Organización Centroamericana y del Caribe de Entidades de Fiscalización Superior (OLACEFS), Auditoria General de la Nación. Recuperado el 23 de agosto de 2012, de: http://www.agn.gov.ar/CTRC/ Documentos\%20CTRC/PERUZZOTTI\%20II.pdf

- Peruzzotti, E. (sf). La política del accountability social en América Latina. Documento de trabajo. Recuperado el 14 de Agosto de 2012, de: http: ebpdn.org/download/ download.php?table $=$ resources\&id= 509 .

- $\quad$ Roth, A. (2008). El análisis de políticas públicas y sus múltiples abordajes teóricos: ¿una discusión irrelevante para América Latina? Ponencia Asociación Colombiana de Ciencia Política. Recuperado el 12 de agosto de 2012, de: http:// congresocienciapolitica.uniandes.edu.co/.

\section{Fuentes Periodísticas}

- $\quad$ Caracol Radio, 4 de marzo de 2011.

- $\quad$ La Silla Vacía, 9 de marzo de 2011.

- $\quad$ Libertad Digital, 20 de octubre de 2010.

- $\quad$ Notiagen, 25 de febrero de 2011

- $\quad$ El Espectador, 18 de enero de 2011.

\section{Páginas oficiales}

- Alianza Cívica http://www.alianzacivica.org.mx/

- $\quad$ Freedom House http://www.freedomhouse.org/

- Latinobarómetro http://www.latinobarometro.org/latino/latinobarometro.jsp

- Misión de Observación Electoral http://www.moe.org.co/webmoe/

- Transparencia Internacional http://www.transparency.org/research 